\title{
Optimizing Multiple Object Tracking and Decision making using neuro-fuzzy
}

\author{
Chineke Amaechi Hyacenth
}

Computer Engineering Department, Micheal Okpara University of Agriculture Umudike, Abia State, Nigeria

\begin{abstract}
How to cite this paper: Chineke Amaechi Hyacenth "Optimizing Multiple Object Tracking and Decision making using neuro-fuzzy" Published in International Journal of Trend in Scientific Research and Development (ijtsrd), ISSN: 24566470, Volume-3 | Issue-3 , April 2019, pp.871-876, URL: https://www.ijtsrd.c om/papers/ijtsrd23 185.pdf

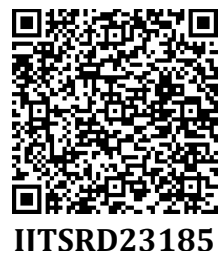

Copyright (C) 2019 by author(s) and International Journal of Trend in Scientific Research and Development Journal. This is an Open Access article distributed under the terms of the Creative Commons

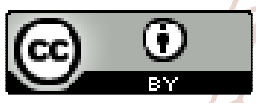
Attribution License (CC BY 4.0) (http://creativecommons.org/licenses/ by/4.0)

\section{INTRODUCTION}

Optimized multiple object tracking and decision making system using neural fuzzy is the topic of this paper. The motivation of writing this paper is to stop fraud, monitoring of activities, identifying stolen objects and to control movement of members of staff in companies. Tracking an object has become a problem let alone tracking multiple objects in a mixed of objects. This must have arisen as a result of having objects with identical size, colour, height, length and the nature of the tracking environment.

\section{Literature Review}

Many renowned authors have worked tirelessly hard to make sure that objects that need to be tracked for one reason or the other are tracked. Some of these renowned authors are (Ramya, 2015) multiple object tracking using support vector machine. This dynamic author did his utmost best but could not incorporate an intelligent agent in it to enhance the efficiency of the tracking.

A robust object detecting and tracking method (Sun, 2014) using fuzzy logic controller. This author achieved at about $58 \%$ efficient but its tracking ability is delayed because he could not imbibe neural network to enhance the rapid tracking ability of vehicle. The author used analog technique for its tracking which could not get a sound result. Real time tracking of a human body (Wren, 2015).Its tracking ability is also small as a result of the absence of an intelligent agent that will highlight the tracking ability.
Optimizing the parametric tracking values, designing membership functions for detecting when there is reduction in efficiency at each stage in the production, monitoring the machine temperature, speed, volume, quality and designing membership function for detecting component failure along the production line and its age deterioration. To train these membership designs to stick strictly to the rules of tracking multiple objects and to design a visual basic sensor for detecting faulty or low standard product. Finally, designing a visual basic sensor for staff monitoring, decision making and a model for multiple object tracking using neuro-fuzzy is proposed in this work.

\section{Methodology}

To use Standard Method from Numerical Optimization for multiple object and decision making to determine the temperature, speed and volume of the objects to be tracked can done using for example

If the quality of goods produced in a company at a temperature $\mathrm{x}$, speed $\mathrm{y}$ and volume $\mathrm{z}$ are 500,400 and 500 respectively and the quantity of the products produced are 100,80 and 120 if at this three stages of production the temperature were varied once, two times and seven times. On the other hand, the speed of production was varied to two times and once twice while the volume of the production in these three stages were six, four and five respectively. Form an optimization mathematical equation for optimizing 

multiple object tracking and decision making using neuro fuzzy.

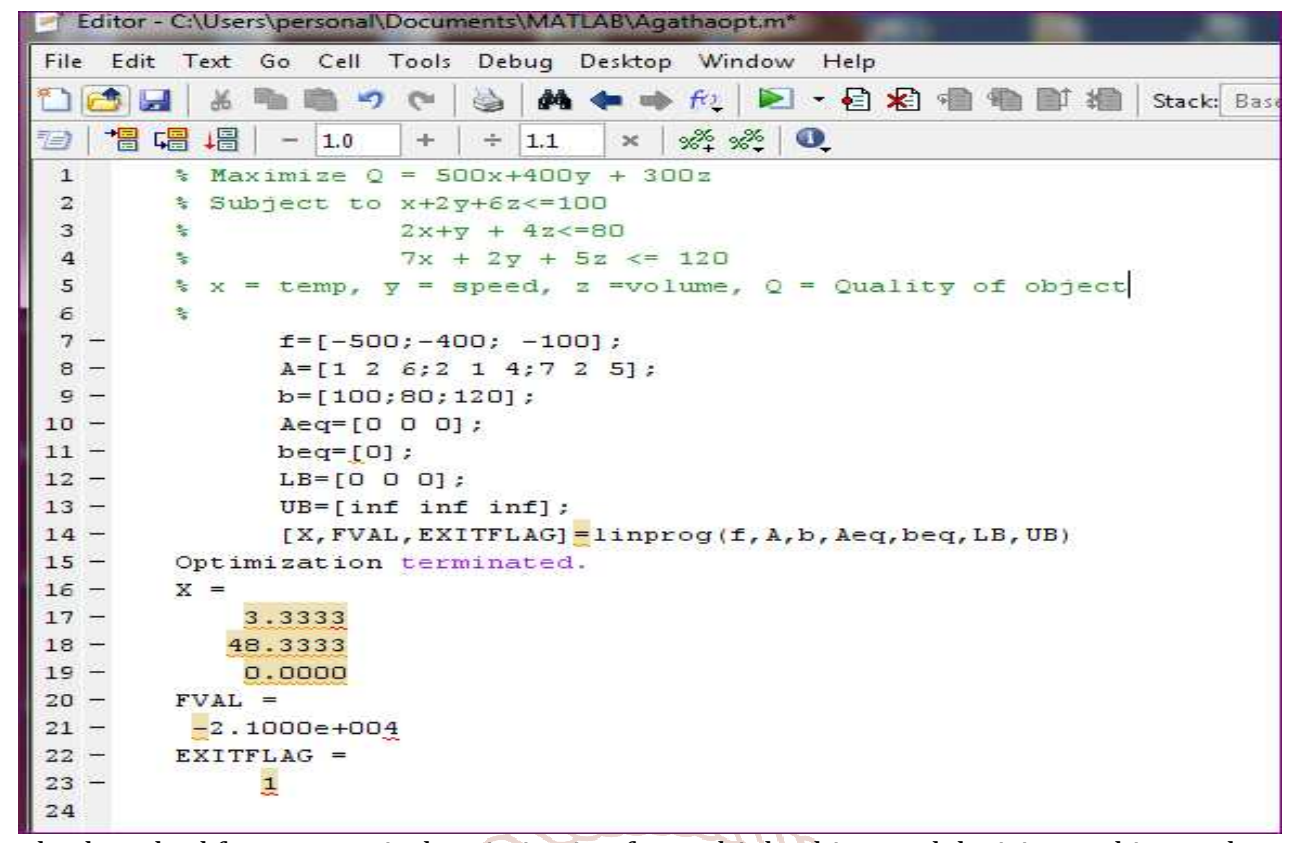

Fig 1 Standard method from numerical optimization for multiple object and decision making to determine the temperature, speed, and volume of the object to be tracked

Fig 1 shows standard method from numerical optimization for multiple object and decision making to determine the temperature speed and volume of the object to be tracked. The optimized result shows that the temp is $3.33^{\wedge} 0 \mathrm{C}$, speed is $48.33 \mathrm{~km} / \mathrm{s}$ and the quality or efficiency of tracking an object is 210000000 ,

\section{To design a membership function for detecting when there is reduction in efficiency at each stage in the production.}

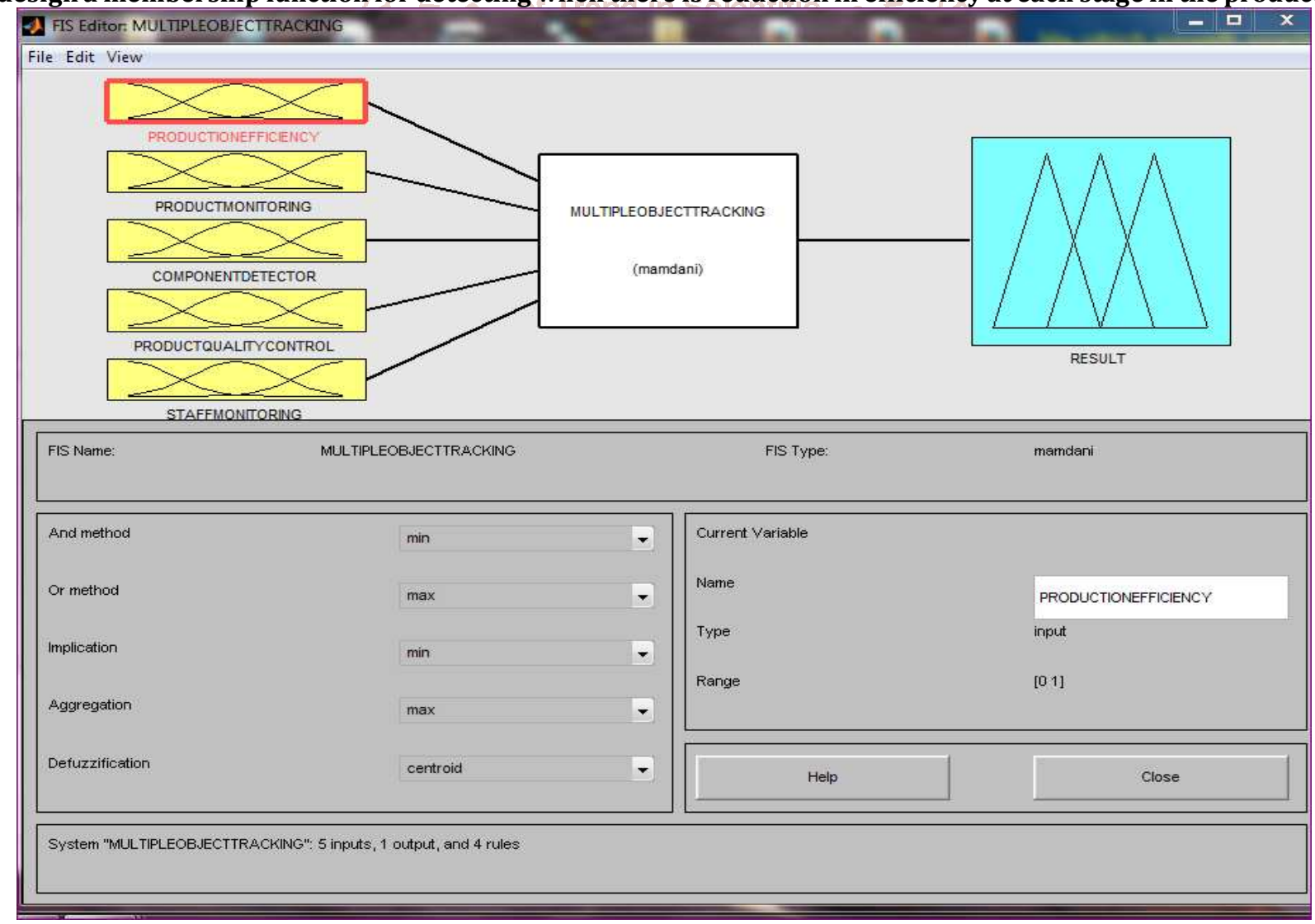

Fig 2 Input and output designed fuzzy inference system for detecting when there is reduction in efficiency at each stage in the production.

Fig 2 above shows the input and output design of fuzzy inference system for detecting when there is reduction in efficiency at each stage in the production. It has five inputs and an output. 
International Journal of Trend in Scientific Research and Development (IJTSRD) @ www.ijtsrd.com eISSN: 2456-6470

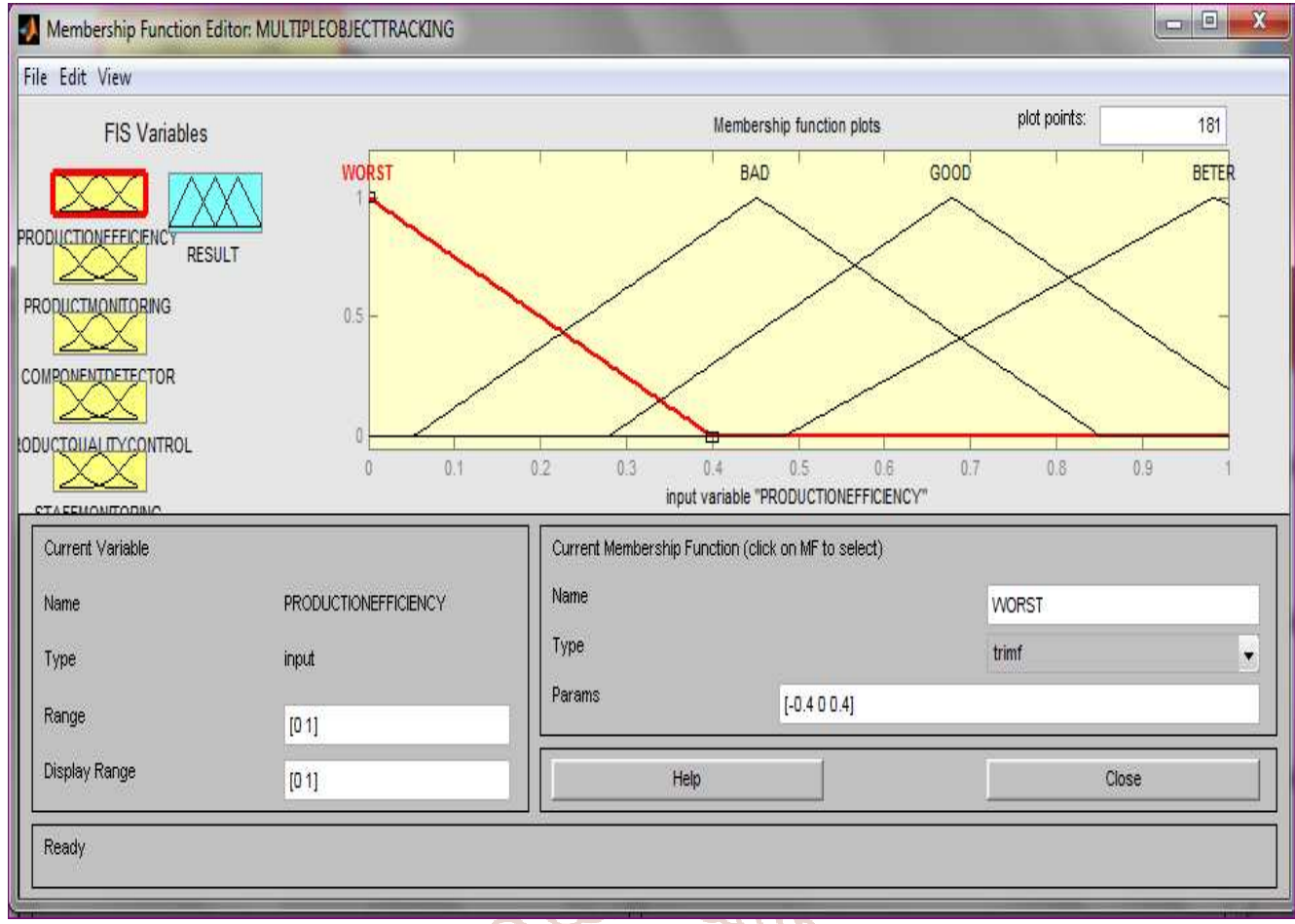

Fig 3 shows Designed membership function for detecting when there is reduction in efficiency at each stage in the production.

Fig 3 above shows designed membership function for detecting when there is reduction in efficiency at each stage in the production It gives the analysis of the production process.

To design a membership function for monitoring machine temperature, speed, volume and quality of the manufactured product

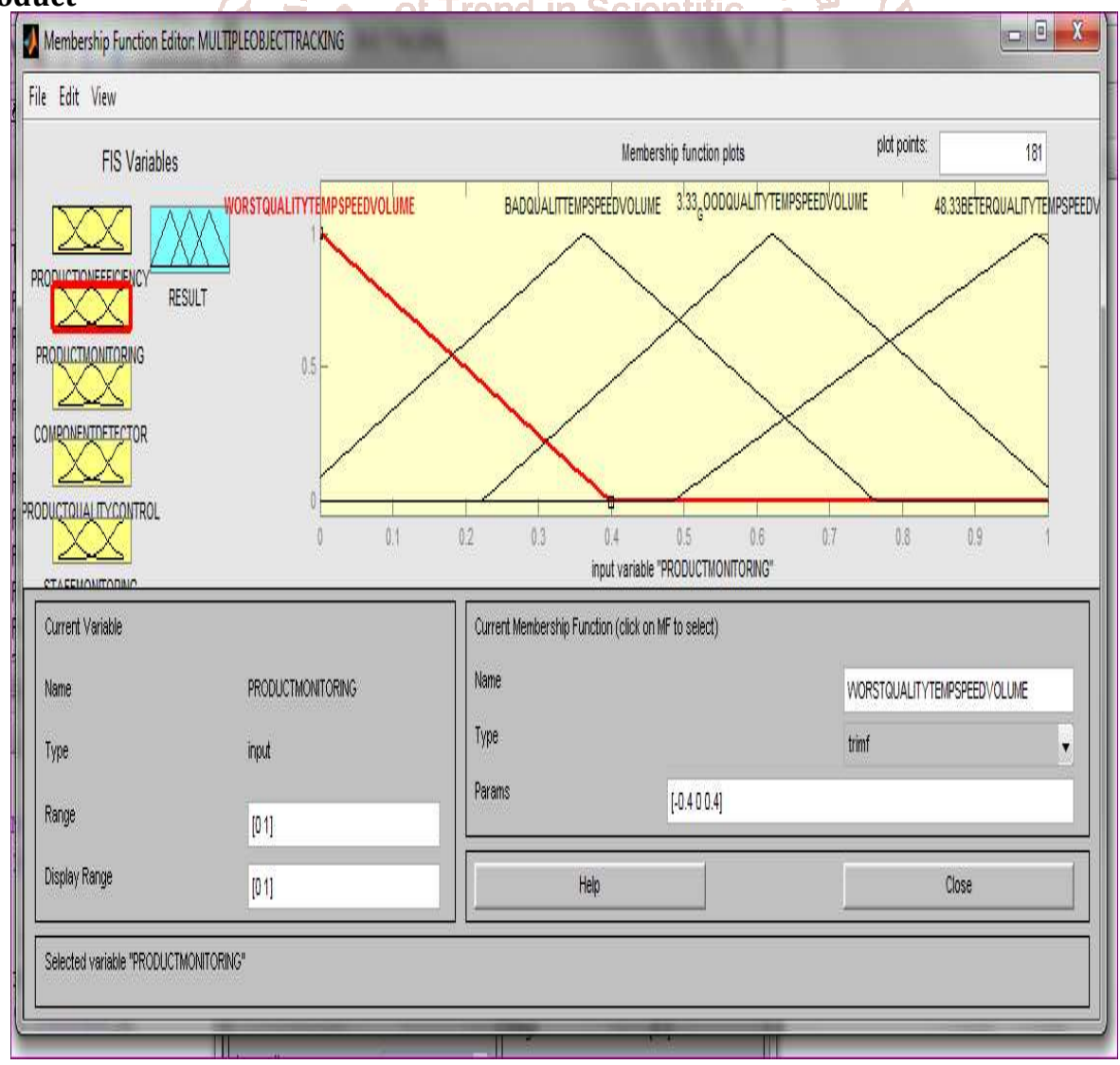

Fig 4 Designed membership function for monitoring machine temperature, speed, volume and quality of the manufactured product

Fig 4 above shows designed membership function for monitoring machine temperature, speed, volume and quality of the manufactured product. 
International Journal of Trend in Scientific Research and Development (IJTSRD) @ www.ijtsrd.com eISSN: 2456-6470

To design a membership function for detecting component failure along the production line and its age deterioration

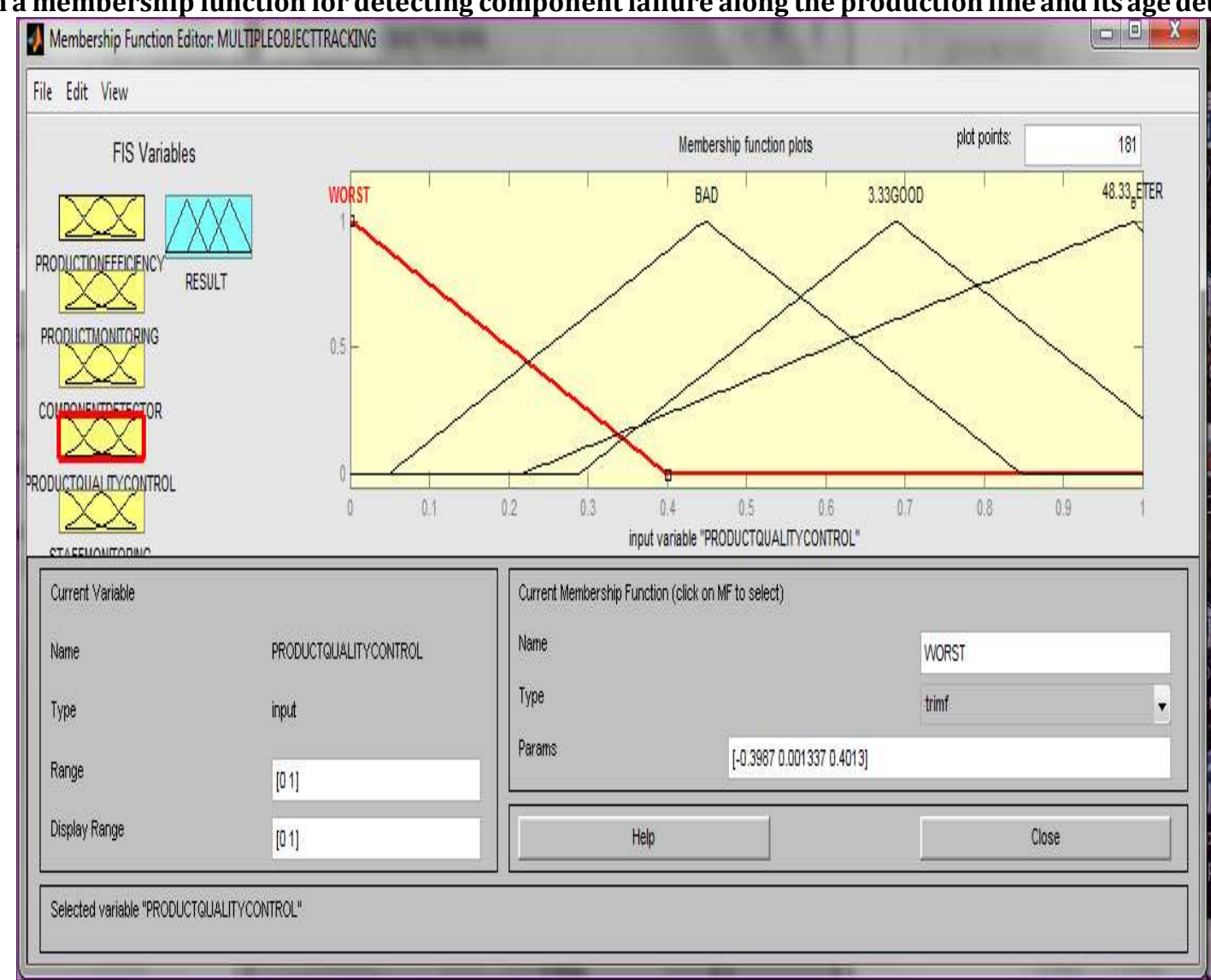

Fig 5 Designed membership function for detecting component failure along the production line and its age deterioration.

Fig 5 above shows designed membership function fotr detecting component failure along the production line and its age deterioration. It gives a perfect analysis of component failure and its age deterioration.

\section{To Train, Validate and Test the Process in i, ii and iii}

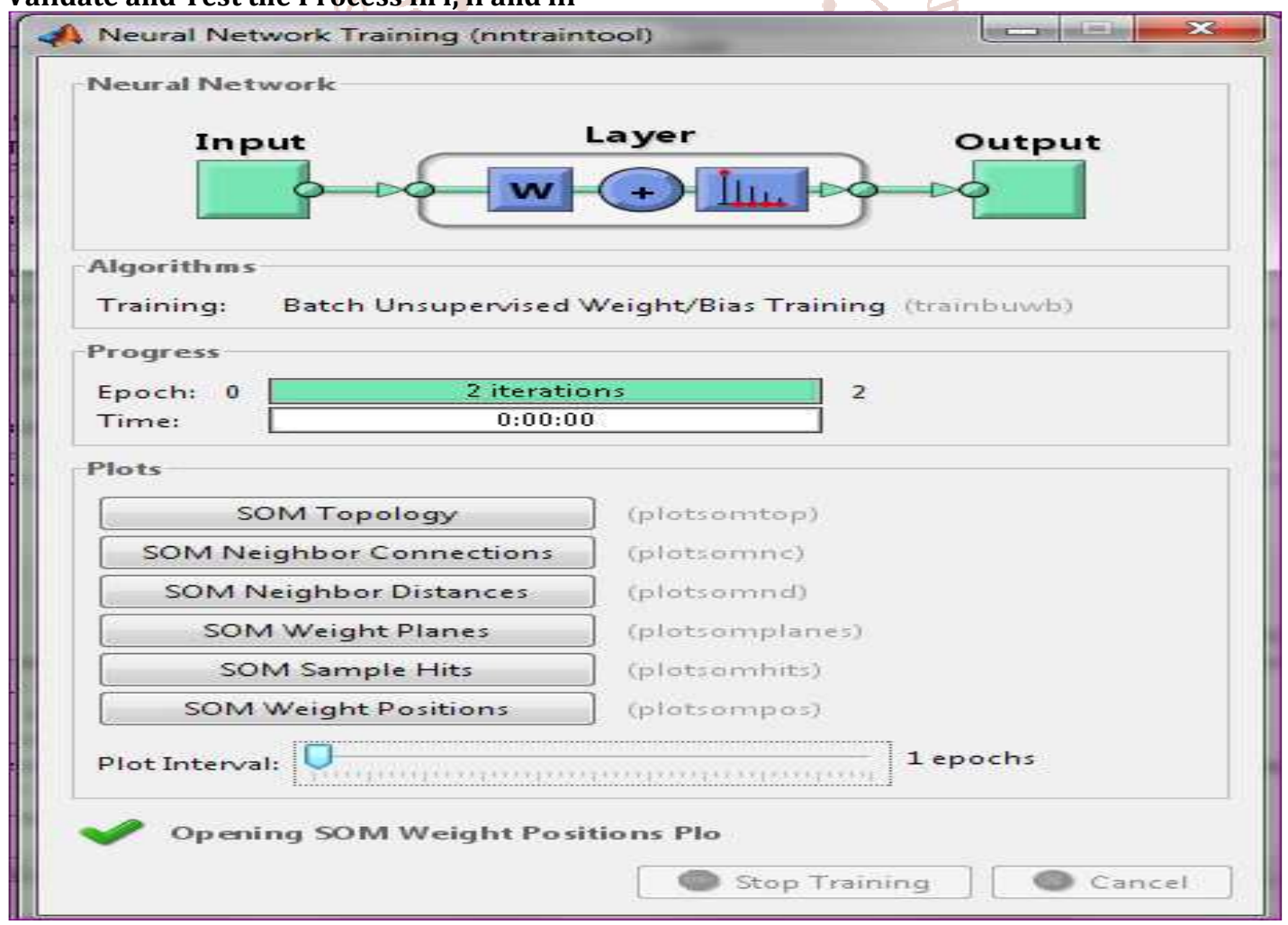

Fig 6 Trained, validated and tested the process in i, ii and iii

Fig 6 above shows trained validated and tested the process .The result of this is to have an effective tracking ability. 
International Journal of Trend in Scientific Research and Development (IJTSRD) @ www.ijtsrd.com eISSN: 2456-6470

To design a model for optimizing multiple object tracking and decision making using neuro -fuzzy

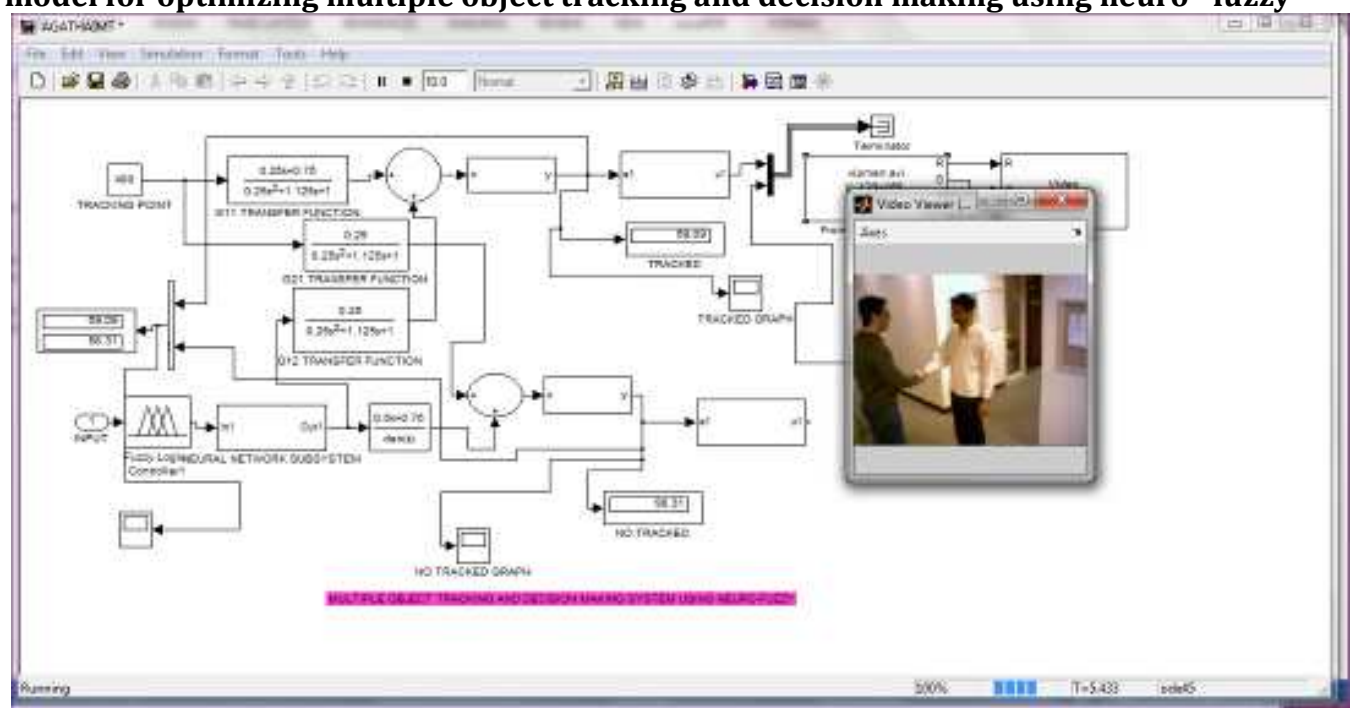

Fig 7 Simulated designed model for optimizing multiple object tracking and decision making using neuro-fuzzy.

Fig 7 above shows simulated designed model for optimizing multiple object tracking and decision making using neuro-fuzzy. It shows the tracking ability of the method applied to track whatsoever the members of the staff is doing.

4. Result Analysis

Table 1 shows Simulated result for optimizing multiple object tracking and decision making using neuro-fuzzy (Tracking)

\begin{tabular}{|c|c|}
\hline Tracking point & Time(s) \\
\hline 0 & 0 \\
\hline 92 & 1 \\
\hline 60 & 2 \\
\hline 70 & 3 \\
\hline 68 & 4 \\
\hline 69 & 5 \\
\hline 69 & 2456 \\
\hline
\end{tabular}

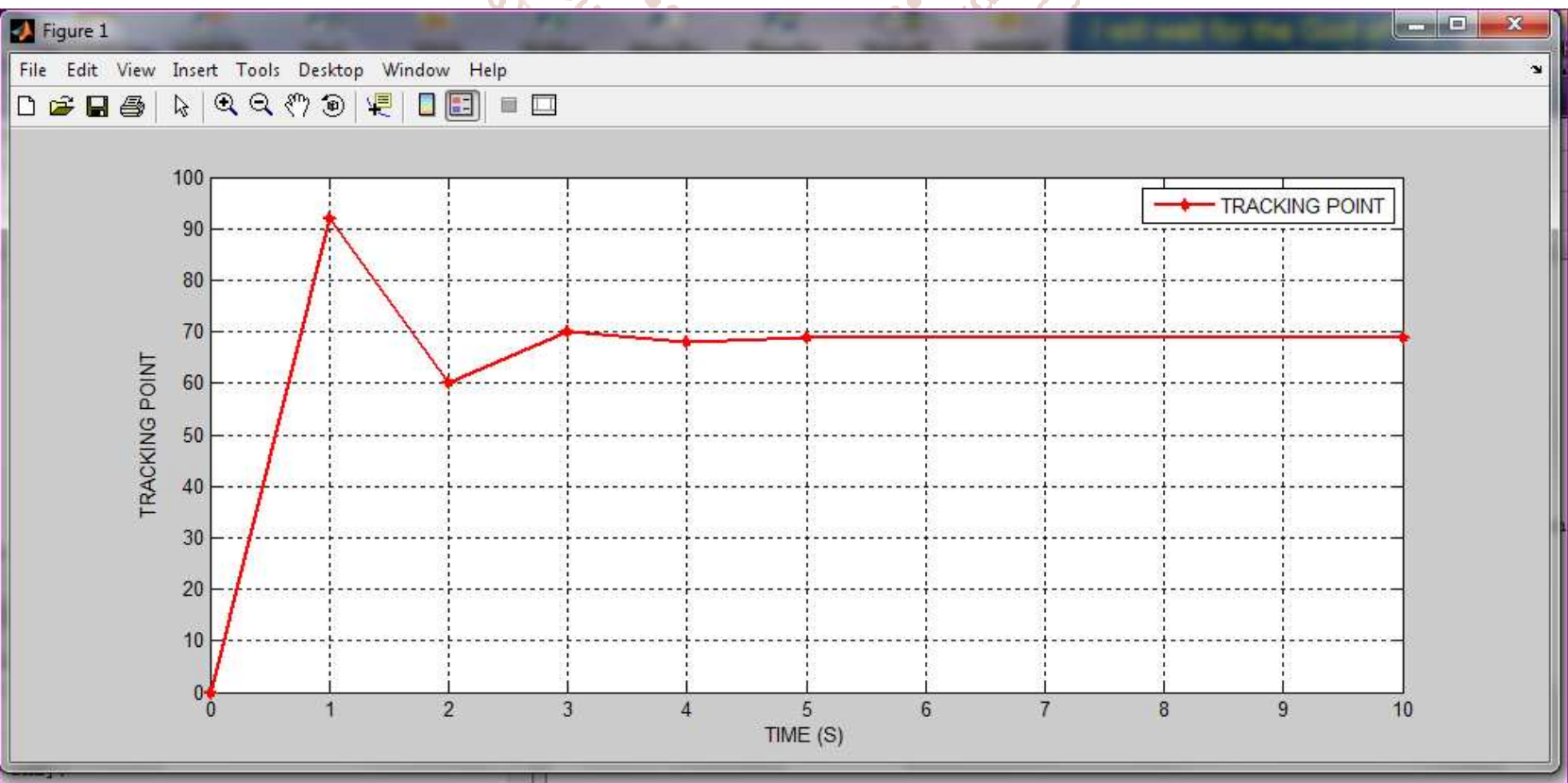

Fig 8 Simulated result for designed model for optimizing multiple object tracking and decision making using neuro fuzzy(Tracked object).

Fig 8 shows simulated result for designed model for optimizing multiple object tracking and decision making using neuro fuzzy ( tracked object). Fig 8 shows that the tracking ability was effective at the coordination of tracking point and time of $(69,5)$ and $(69,5)$ respectively. 
Table 2 Simulated result for optimizing multiple object tracking and decision making using neuro-fuzzy(none tracking)

\begin{tabular}{|c|c|}
\hline Nonetracking point & Time(s) \\
\hline 0 & 0 \\
\hline 40 & 1 \\
\hline 98 & 2 \\
\hline 100 & 3 \\
\hline 105 & 4 \\
\hline 109.6 & 5 \\
\hline 109.6 & 10 \\
\hline
\end{tabular}

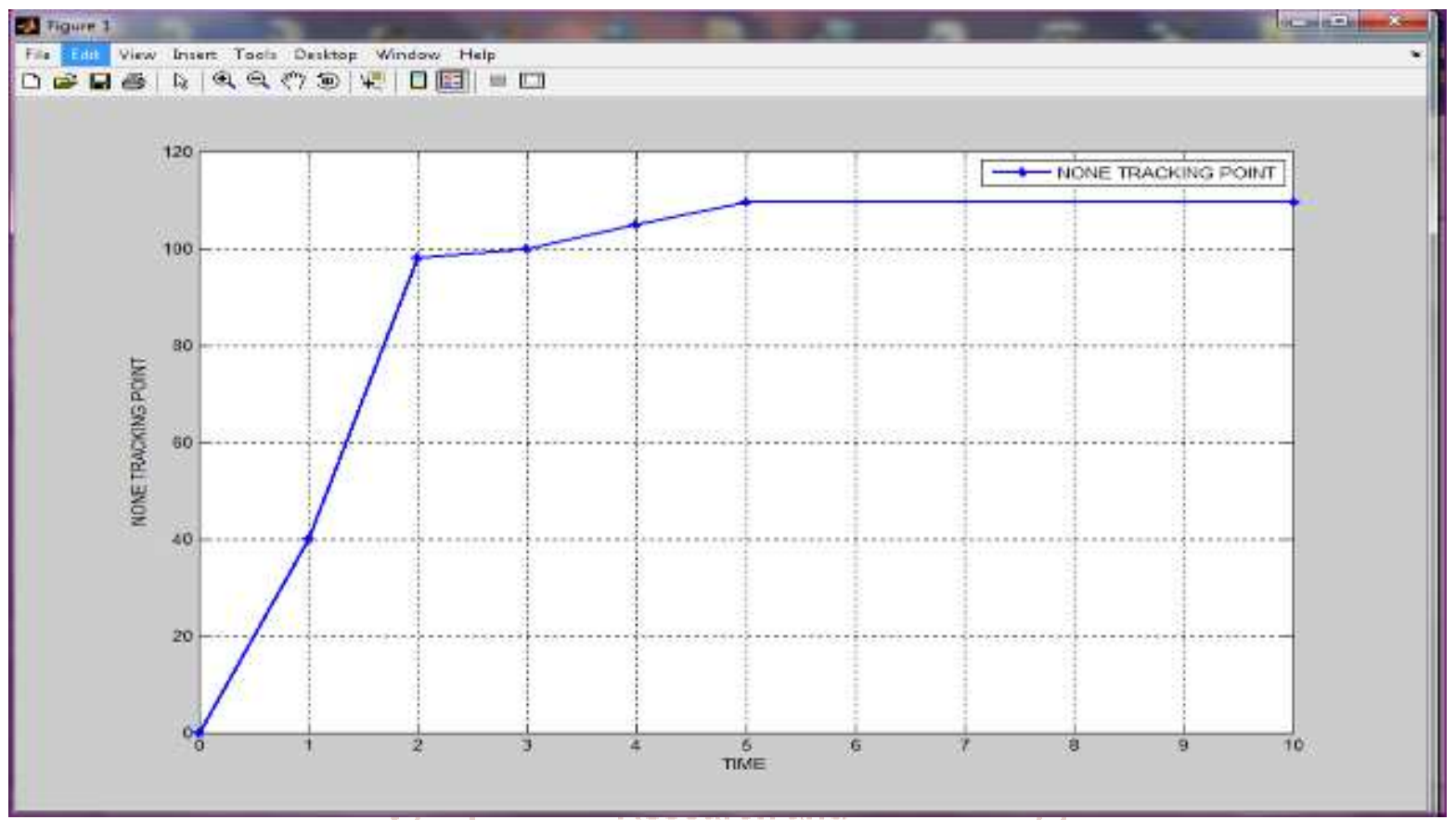

Fig 9 Simulated result for designed model for optimizing multiple object tracking and decision making using neuro -fuzzy (No object Tracked)

Fig 9 shows simulated result for designed model for optimizing multiple object tracking and decision making using neuro-fuzzy (No object tracked). Fig 9 shows that no object was tracked at the coordination of none tracking point and time of $(109.6,5)$ and $(109.6,10)$.

\section{Conclusion}

The tracking of stolen object in the society, industries, and tracking of bad goods as at the time of production has become a very big problem in our country. This can be over come by This can be overcome by using Optimizing multiple object tracking and decision making using neuro -fuzzy. This is done by optimizing the parametric tracking values, designing membership functions for detecting when there is reduction in efficiency at each stage in the production, monitoring the machine temperature, speed, volume, quality and designing membership function for detecting component failure along the production line and its age deterioration coupled with staff behavior in the company. To train these membership designs to stick strictly to the rules of tracking multiple objects and designing a model for multiple object tracking using neuro-fuzzy.

\section{References}

[1] Sun John robust object detecting and tracking using fuzzy logic controller (2014)

[2] Ramya Paul, multiple object tracking using support vector machine (2015)

[3] 3 Wren Peterson Real time tracking of a human body 2015 